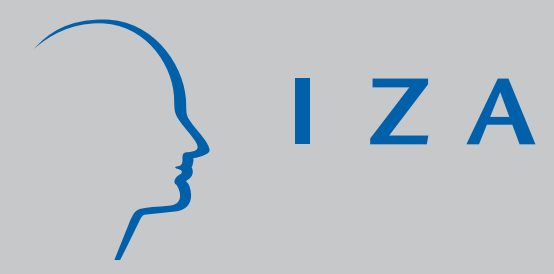

IZADP No. 2628

Equilibrium Unemployment with Outsourcing Under Labour Market Imperfections

Erkki Koskela

Rune Stenbacka

February 2007 


\title{
Equilibrium Unemployment with Outsourcing under Labour Market Imperfections
}

\author{
Erkki Koskela \\ University of Helsinki \\ and IZA \\ Rune Stenbacka \\ Göteborg University and \\ Swedish School of Economics, Helsinki
}

Discussion Paper No. 2628

February 2007

IZA

P.O. Box 7240

53072 Bonn

Germany

Phone: +49-228-3894-0

Fax: +49-228-3894-180

E-mail: iza@iza.org

Any opinions expressed here are those of the author(s) and not those of the institute. Research disseminated by IZA may include views on policy, but the institute itself takes no institutional policy positions.

The Institute for the Study of Labor (IZA) in Bonn is a local and virtual international research center and a place of communication between science, politics and business. IZA is an independent nonprofit company supported by Deutsche Post World Net. The center is associated with the University of Bonn and offers a stimulating research environment through its research networks, research support, and visitors and doctoral programs. IZA engages in (i) original and internationally competitive research in all fields of labor economics, (ii) development of policy concepts, and (iii) dissemination of research results and concepts to the interested public.

IZA Discussion Papers often represent preliminary work and are circulated to encourage discussion. Citation of such a paper should account for its provisional character. A revised version may be available directly from the author. 
IZA Discussion Paper No. 2628

February 2007

\section{ABSTRACT}

\section{Equilibrium Unemployment with Outsourcing under Labour Market Imperfections ${ }^{*}$}

We study both the various consequences and the incentives of outsourcing. We argue that the wage elasticity of labour demand is increasing as a function of the share of outsourcing, which is importantly a result consistent with existing empirical research. Furthermore, we show that a production mode with a higher proportion of outsourcing activity reduces the negotiated wage in the high-wage country with an imperfectly competitive labour market so that outsourcing reduces equilibrium unemployment. Finally, we characterize the optimal production mode and show that stronger labour market imperfections lead to a production mode with a higher share of outsourcing.

JEL Classification: E23, E24, J51, J64

Keywords: outsourcing, labour market imperfections, equilibrium unemployment

Corresponding author:

Erkki Koskela

Department of Economics

University of Helsinki

P.O. Box 17 (Arkadiankatu 7)

00014 Helsinki

Finland

E-mail: erkki.koskela@helsinki.fi

\footnotetext{
* The authors thank the Research Unit of Economic Structures and Growth (RUESG), financed by Academy of Finland, University of Helsinki, Yrjö Jahnsson Foundation, Bank of Finland and Nokia Group, for financial support. Koskela also thanks Academy of Finland (grant No. 1109089) for further financial support.
} 


\section{Introduction}

On a global scale wage differences are enormous across countries ranging from, for example, 1,10 € per hour in China to almost $28 €$ per hour in Germany (see, e.g. Sinn (2006)). Wage differences like this constitute a central explanation for the increasingly dominant business practice of international outsourcing across a wide range of industries. For example, Business Week (2003), Amiti and Wei (2004) as well as Rishi and Saxena (2003) refer to the huge difference in labour costs as the key explanation for the strong increase in outsourcing of both manufacturing and services to countries with low labour costs. However, the exploitation of the marginal cost advantages offered by production in low-wage countries typically requires that the firms make sunk investments into the establishment of networks of suppliers in the relevant low-wage countries.

In countries with strong labour market imperfections the labour unions, and sometimes citizens more generally, typically express deep concerns when facing the challenge of large-scale outsourcing. These concerns often seem to focus on the consequences of large-scale outsourcing for employment in high-wage countries. This is the topic of this article. More precisely, we design a model to answer the following questions: What is the effect of a commitment to outsourcing on wage formation in an imperfectly competitive labour market where labour unions and firms negotiate over wages? What are the associated effects on equilibrium unemployment in a country with such labour market imperfections? We also explore the relationship between outsourcing and wage formation in the other direction, by asking: How does the presence of labour market imperfections in the high-wage country impact on the outsourcing incentives of firms? Will stronger labour market imperfections increase the optimal scale of outsourcing?

We find that the wage elasticity of labour demand is increasing as a function of the share of outsourcing, a result consistent with existing empirical research, as we will see below. Furthermore, within the framework of our model we show that a production mode with a higher proportion of outsourcing reduces the negotiated wage in the high-wage country with an imperfectly competitive labour market. For this reason outsourcing reduces equilibrium unemployment. Finally, we characterize the 
optimal production mode and show that stronger labour market imperfections lead to a production mode with a higher share of outsourcing.

Despite the apparent significance of the issue it is somewhat surprising to observe that the existing research has explored the implications international outsourcing for equilibrium unemployment in the presence of labour market imperfections only to a fairly limited extent. Below we briefly describe the relevant literature focusing on this issue so as to highlight how this study adds to our knowledge.

Danthine and Hunt (1994) have both theoretically and empirically studied the effects of international outsourcing and foreign direct investment on wage formation in the home country. They showed that higher product market integration implies intensified product market competition, which moderates wage increases in unionised labour markets. Zhao (1998) has studied the impact of foreign direct investment on wages and employment, when labour-management bargaining is industry-wide. He argued that foreign direct investment reduces the negotiated wage if the union focuses on wages. Glass and Saggi (2001) have studied the causes of outsourcing and its effects, finding that higher international outsourcing lowers both the relative wage of workers and increases the returns from innovation.

Skaksen and Sorensen (2001) have studied the effects on trade unions of firms' foreign direct investments, which are made prior to the stage of the wage bargaining. They argued that if there is a high degree of substitutability (complementarity) between the activities in the home country and in the host country, then it is likely that foreign direct investments reduce (increase) negotiated wages. Skaksen (2004) has analyzed the implications of outsourcing, in terms of both potential (non-realized) and realized international outsourcing, for wage setting and employment under imperfectly competitive labour markets. He assumed that the firms do not commit themselves to outsourcing prior wage negotiation, but that the outsourcing decisions are made after the wage negotiations.

Lommerud, Meland and Straume (2005) have analyzed the incentives of firms operating in unionized industries to outsource the production of intermediate goods to foreign low-cost subcontractors. They argue that firms will have returns from outsourcing if they face stronger unions, contributing to higher domestic wages. Furthermore, they show that intensified product market competition will increase the incentives for international outsourcing. However, since their analysis is restricted to 
a partial equilibrium model they do not analyze the relationship between equilibrium unemployment and international outsourcing,

In terms of empirics Feenstra and Hanson (1999) have studied the impact of foreign outsourcing and technology on wages using U.S. data over the period 19791990. According to their findings, wages of low-skilled workers have fallen relative to those of high-skilled workers. Recently, Senses (2006) has argued that an increased probability of outsourcing associated with a decline in foreign intermediate input prices and an increase in the elasticity of substitution between foreign and domestic inputs might increase the wage elasticity of labour demand. He has provided relevant empirical evidence, according to which a production mode with more outsourcing increases the wage elasticity of labour demand.

Our study proceeds as follows. Section II presents the basic structure of the model as well as the time sequence of the decisions in terms of outsourcing, wage bargaining and labour demand. Labour demand by firms is studied in section III, whereas we focus on wage determination through Nash bargaining in Section IV. Section V explores how the production mode affects equilibrium unemployment. In section VI we investigate the optimal outsourcing decision in the presence of labour market imperfections. Finally, we present concluding comments in Section VII.

\section{Basic Framework}

We focus on a model with imperfections in the domestic labour market. In the long run, at stage 1, firms establish a network for foreign outsourcing. Outsourced production in a foreign low-wage country has the advantage of avoiding the wage mark-ups imposed by the unions in the firm's domestic high-wage country. More precisely, with outsourced production the firm can acquire labour input at the factor price c, which is lower than the negotiated wage $\mathrm{w}$ in the high-wage country. However, there is a fixed (sunk) cost of establishing capacity for foreign outsourced production. In order to exploit $M$ units of outsourced labour input the firm has to make the irreversible investment $g(M)$ with the properties that $g^{\prime}(M)>0$ and $g^{\prime \prime}(M)>0$. 
The outsourcing decisions serve as commitments relative to wage negotiation and employment decisions in the home country. Thus, the outsourcing decisions are made in anticipation of their effects on wage setting and labour demand. A stage 2 there is wage negotiation between firms and labour unions and this bargaining is conducted conditional on the outsourcing commitments. The wage negotiations in their turn take place in anticipation of the consequences for labour demand. At stage 3 firms make employment decisions by taking the negotiated wage rate and the production mode as given.

We summarize the time sequence of decisions in Figure 1. In the subsequent sections we derive the decisions taking place at different stages by using backward induction.

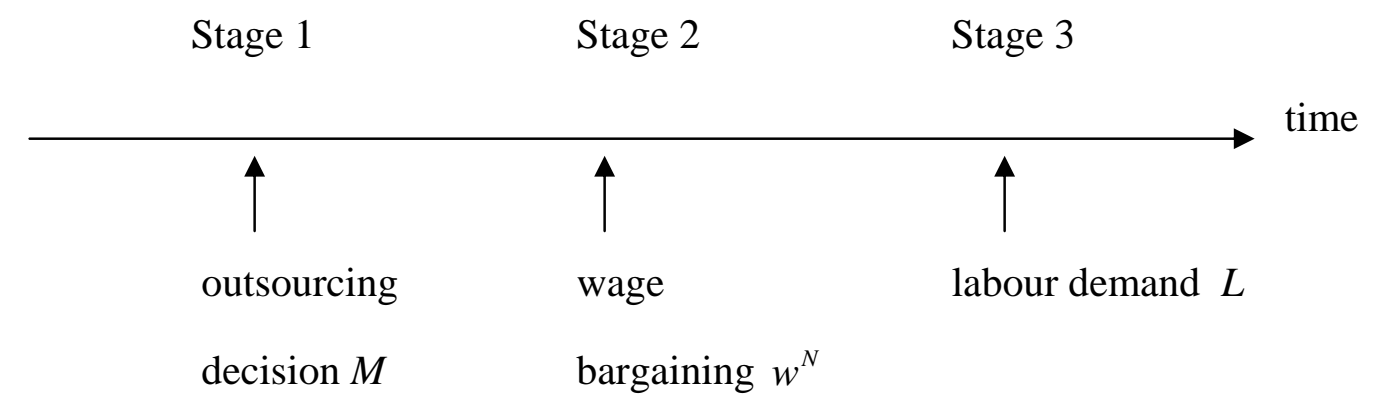

Figure 1: Time sequence of decisions

This timing structure captures the idea of long-term production mode decisions, which are inflexible at the stage when the wage negotiations are undertaken. Such a timing structure seems plausible when the implementation of a production mode with outsourcing requires irreversible long-term investments for the establishment of a network of component suppliers. Of course, in principle, the relative timing between the negotiated wage setting and the production mode decisions could also be reversed so as to capture that the negotiated wage serves as a long-term commitment relative to the production mode decision. This has been done by Skaksen (2004) using a CobbDouglas production function with domestic and foreign labour.

We postulate a CES production function according to 


$$
R(M, L)=\left(\left[(1-a) M^{\frac{\sigma-1}{\sigma}}+a L^{\frac{\sigma-1}{\sigma}}\right]^{\frac{\sigma}{\sigma-1}}\right)^{\rho},
$$

where $M$ denotes the firm's labour input acquired from external suppliers through outsourcing, $L$ is the amount of labour employed in-house, and $a, \sigma$ and $\rho$ are parameters satisfying $0<a<1$, and $0<\rho<1$, respectively. ${ }^{1}$ In (1) $a$ is the distribution parameter (see e.g. Arrow et al (1961)) between the production factors, while $\sigma$ captures the elasticity of substitution between the two different types of labour inputs. In what follows we assume that $0<\sigma<1$. This can be justified as follows: Under this assumption a production mode with more outsourcing increases the wage elasticity of labour demand, as we will show in the next section. Senses (2006) has provided relevant empirical evidence, which lies in conformity with this implication. Through the parameter $\rho$ the production function (1) exhibits diminishing returns to scale. Overall, this production function introduces, as we will see, interesting relationships between the production mode and equilibrium unemployment both in the short and in the long run, i.e. no matter whether the production mode is exogenous or endogenous.

\section{Labour Demand}

The firm decides on domestic in-house employment so as to maximize the profit function

$$
\underbrace{\max }_{(L)} \pi=R(M, L)-w L
$$

by taking both the negotiated wage rate $w$ and the established capacity for outsourced labour inputs $M$ as given. The necessary first-order condition associated with (2) is

$$
\pi_{L}=R_{L}-w=0
$$

Ethier (2005) has introduced a somewhat related production function to analyze the decision between outsourcing and in house production in his analysis concerning the effect of globalization on the skill premium. 
and the associated second-order condition $\pi_{L L}=R_{L L}<0$ holds true. The formulation (3) is an implicit characterization of labour demand capturing the familiar idea that the firm expands in-house employment until marginal return of labour coincides with the wage. For the CES production function (1) the first-order condition (3) can be expressed as $\left[(1-a) M^{\frac{\sigma-1}{\sigma}}+a L^{\frac{\sigma-1}{\sigma}}\right]^{\frac{\sigma(\rho-1)+1}{\sigma-1}} \rho a L^{-\frac{1}{\sigma}}=w$. From this we can deduce the labour demand in terms of outsourced labour inputs, wage rate, elasticity of substitution and parameters $a$ and $\rho$ as follows

$$
L^{*}=M^{\sigma(1-\rho)+1}\left[\frac{1}{1-a}\left(\frac{w}{\rho a}\right)^{\frac{\sigma-1}{\sigma(\rho-1)+1}}-\frac{a}{1-a}\right]^{\frac{\sigma(\rho-1)+1}{(1-\sigma)}}
$$

The wage elasticity of labour demand, which turns out to be important later on, can be calculated to be (see Appendix A)

$$
\eta\left(\frac{M}{L}\right)=-\frac{L_{w}^{*} w}{L^{*}}=\frac{\sigma\left(1+\frac{1-a}{a}\left(\frac{M}{L}\right)^{\frac{\sigma-1}{\sigma}}\right)}{\left[\sigma(1-\rho)+\frac{1-a}{a}\left(\frac{M}{L}\right)^{\frac{\sigma-1}{\sigma}}\right]},
$$

where $m \equiv M / L$ denotes the ratio between the labour inputs acquired through outsourcing and domestic in-house employment. For short and admittedly somewhat incompletely, we will subsequently refer to $m$ as the share of outsourced production.

From (4) we can conclude that the wage elasticity of labour demand, $\eta\left(\frac{M}{L}\right)>1$, depends on two structural features in addition to the parameters $a$ and $\rho$ of the production function: (i) the elasticity of substitution between the labour inputs acquired through outsourcing and domestic in-house employment $(\sigma)$ and (ii) the production mode, or, more precisely, the share of outsourced production ( $m \equiv M / L$ ).

We now ask: What is the effect of the production mode on the wage elasticity of labour demand? This is an important question to answer as the wage elasticity in the 
case of CES production function affects the negotiated wage. Differentiating (4) with respect to $M$ yields

$$
\eta_{M}=\frac{\frac{1-a}{a}(\sigma-1)(\sigma(1-\rho)-1)\left(\frac{M}{L}\right)^{-\frac{1}{\sigma}} \frac{1}{L}}{\left[\sigma(1-\rho)+\frac{1-a}{a}\left(\frac{M}{L}\right)^{\frac{\sigma-1}{\sigma}}\right]^{2}}
$$

Under decreasing returns to scale $(\rho<1)$ we can formulate the following property from (5).

Proposition 1 The wage elasticity of labour demand depends on the elasticity of substitution between labour inputs acquired through outsourcing and in-house employment. The wage elasticity of labour is an increasing function of the share of outsourced production when $\sigma<1$.

According to (5) the technological elasticity of substitution between the production factors $L$ and $M$ is of primary importance for the relationship between the share of outsourced production $(m \equiv M / L)$ and the wage elasticity of labour demand. When $M$ and $L$ are 'gross complements' $(\sigma<1)$, a higher $m \equiv M / L$ will increase the wage elasticity of labour demand due to the fact that it will raise the home country labour share.

\section{Wage Determination via Nash Bargaining}

We now proceed to investigate wage determination and continue to consider the acquired outsourced production $M$ as given. We apply the Nash bargaining solution following the 'right-to-manage' approach so that the wage negotiations take place in anticipation of optimal employment decisions by the firms (see e.g. Cahuc and Zylberberg (2004), Chapter 7). The union's objective function is assumed to be $\hat{U}=w L^{*}+b\left(N-L^{*}\right)$, where $b$ is the (exogenous) outside option available to union members and $N$ is the number of union members $\left(N>L^{*}\right)$. The threat points for the 
union and for the representative firm are $\pi^{o}=-c M-g(M)$ and $U^{o}=N b$, respectively. Hence we have that $U=\hat{U}-N b=L^{*}(w-b)$ and $\pi=\hat{\pi}+c M+g(M)=R\left(M, L^{*}\right)-w L^{*}$.

Following the Nash bargaining approach the firm and the labour union negotiate with respect to the wage so as to solve the optimization problem

$$
\underbrace{\max }_{(w)} \Omega=\left[L^{*}(w-b)\right]^{\beta}\left[R\left(M, L^{*}\right)-w L^{*}\right]^{1-\beta} \quad \text { s.t. } \pi_{L}=0
$$

where the relative bargaining power of the union is $\beta$ and that of the firm is $(1-\beta)$. The necessary first-order condition for the negotiated wage can be written as

$$
\beta \frac{U_{w}}{U}+(1-\beta) \frac{\pi_{w}}{\pi}=0
$$

where

$$
\frac{U_{w}}{U}=\frac{1}{w} \frac{\left[w\left(1-\eta\left(\frac{M}{L}\right)\right)+b \eta\left(\frac{M}{L}\right)\right]}{w-b}
$$

and

$$
\frac{\pi_{w}}{\pi}=-\frac{1}{w} \frac{w L^{*}}{\pi}=-\frac{1}{w} \frac{R_{L} L^{*}}{\left[R-R_{L} L^{*}\right]}=-\frac{1}{w} \frac{a}{1-a}\left(\frac{M}{L}\right)^{\frac{1-\sigma}{\sigma}} .
$$

Substituting the expressions (8a) and (8b) into the first-order condition (7) yields, after some rearrangement, the following Nash bargaining solution for the wage rate

$$
w^{N}=\left[1+\frac{\beta}{\beta\left(\eta\left(\frac{M}{L}\right)-1\right)+(1-\beta) \frac{a}{1-a}\left(\frac{M}{L}\right)^{\frac{1-\sigma}{\sigma}}}\right] b .
$$


According to (9) the negotiated wage rate depends positively on the outside option $(b)$ and on the relative bargaining power of the labour union $(\beta)$, while negatively on the wage elasticity of labour demand $(\eta)$. The negotiated wage is affected by the share of outsourced production $(M / L)$ both directly and indirectly though its impact on the wage elasticity of labour demand in a way, which depends on the magnitude of the elasticity of substitution between the two types of labour input.

By differentiating the negotiated wage (9) with respect to $M$ we find under the assumption $0<\sigma<1$ that

$$
\frac{\partial w^{N}}{\partial M}=\frac{-\beta b\left[\beta \eta_{M}\left(\frac{M}{L}\right)+(1-\beta) \frac{1-\sigma}{\sigma} \frac{a}{1-a} \frac{1}{L}\left(\frac{M}{L}\right)^{\frac{1-2 \sigma}{\sigma}}\right]}{\left[\beta\left(\eta\left(\frac{M}{L}\right)-1\right)+(1-\beta) \frac{a}{1-a}\left(\frac{M}{L}\right)^{\frac{1-\sigma}{\sigma}}\right]^{2}}<0
$$

The relationship (10) characterizes how the share of outsourced production can serve as a strategic commitment device, with the effect of inducing wage moderation. The technological features summarized by the elasticity of substitution between the two types of labour inputs play an important role for this wage-moderating effect of outsourcing. The intuition for this wage-moderating effect can be understood as follows: A higher outsourcing-in-house production ratio decreases the negotiated wage rate via two channels: (1) it becomes harder for the union to extract rent in negotiations because of the induced higher wage elasticity of labour demand, and (2) a higher outsourcing-in-house production ratio increases the negative effect of the wage rate on the profit, i.e. $\frac{\partial}{\partial M}\left(\frac{\pi_{w}}{\pi}\right)<0$ when $\sigma<1$ and thus moderates wage formation.

We now summarize our analysis of the wage determination in 
Proposition 2 The negotiated wage rate depends negatively on the wage elasticity of labour demand and a higher share of outsourced production will decrease the negotiated wage rate when $\sigma<1$.

From the negotiated wage (9) we can infer a number of properties for special cases. If all the bargaining power lies with the union $(\beta=1)$, the Nash bargaining solution is simplified to the monopoly union solution

$$
w^{M}=\frac{\eta\left(\frac{M}{L}\right)}{\eta\left(\frac{M}{L}\right)-1} b
$$

according to which the wage mark-up depends negatively on the wage elasticity of labour demand, which is a function of the share of outsourced production. In the opposite case with all the bargaining power concentrated to the firm ( $\beta=0)$, the relationship between the negotiated wage and the production mode ratio disappears. In this case the negotiated wage converges to the competitive wage with $w^{C}=b$, i.e. the wage mark-up is eroded. Intuitively this seems to make sense for the following reason. The share of outsourced production serves as a strategic commitment device, which will affect the distribution of the rents, achieved through bargaining, in imperfectly competitive labour markets. Once the labour market imperfections are eroded the production mode can no longer play such a strategic role.

\section{The Effect of Outsourcing on Equilibrium Unemployment}

We now move on to explore the determinants of equilibrium unemployment in a general equilibrium framework. We are in this section interested in the relationships between the exogenous production mode (outsourcing) and equilibrium unemployment.

According to (9) the negotiated wage rate in industry $i$ is of the form $w^{N}=A b$, where the mark-up factor is 


$$
A=1+\frac{\beta}{\beta\left(\eta\left(\frac{M}{L}\right)-1\right)+(1-\beta) \frac{a}{1-a}\left(\frac{M}{L}\right)^{\frac{1-\sigma}{\sigma}}} .
$$

In the presence of the positive relative bargaining power of the labour union the mark-up $\frac{w^{N}}{b}=A>1$ because the wage elasticity of labour demand $\eta>1$. This markup factor is, in principle, industry-specific. In a general equilibrium the term $b$ should be re-interpreted as the endogenous outside option, which we specify in a conventional way as

$$
b=(1-u) w^{N}+u B,
$$

where $u$ is the unemployment rate, $B$ captures the unemployment benefit and $w^{N}$ denotes the negotiated wage rate in all identical industries in the economy (see Nickell and Layard (1999) p. 3048-3049 for a further discussion). Assuming a constant benefit replacement ratio $q=B / w^{N}$ and substituting (12) for $b$ into the Nash bargaining solution (9) yields the equilibrium unemployment

$$
u^{N}=\frac{1}{1-q}\left[1-\frac{1}{A}\right]
$$

where the wage mark-up $A$ is given by (11).

According to (13) a higher benefit-replacement ratio, $q$, and a higher mark-up in the wage determination, $A$, will increase equilibrium unemployment. Further, from the mark-ups in the wage determination we can conclude that higher wage elasticity of labour demand will decrease equilibrium unemployment.

As for the impact of the production mode (the outsourcing) on equilibrium unemployment we initially observe under $0<\sigma<1$ that

$$
A_{M}=\frac{-\beta b\left[\beta \eta_{M}\left(\frac{M}{L}\right)+(1-\beta) \frac{1-\sigma}{\sigma} \frac{a}{1-a} \frac{1}{L}\left(\frac{M}{L}\right)^{\frac{1-2 \sigma}{\sigma}}\right]}{\left[\beta\left(\eta\left(\frac{M}{L}\right)-1\right)+(1-\beta) \frac{a}{1-a}\left(\frac{M}{L}\right)^{\frac{1-\sigma}{\sigma}}\right]^{2}}<0
$$


This offers a characterization of the production mode as a strategic commitment device with employment effects. Because it holds true that $\frac{\partial w^{N}}{\partial M}=A_{M} b$, we can explore the effect of the share of outsourced production on equilibrium unemployment by combining (13) and (14). According to Proposition 2 the relationship between the outsourcing commitment and wage formation and thereby the relationship between the production mode and equilibrium unemployment depends on the size of the elasticity of substitution between the two types of labour inputs.

Our new findings concerning the determinants of equilibrium unemployment with exogenous production modes can now be summarized in

Proposition 3 A production mode with a higher share of outsourced production will reduce equilibrium unemployment when $\sigma<1$.

Proposition 3 predicts that there is a systematic relationship between the production mode and equilibrium unemployment such that a higher share of outsourced production promotes employment in the high-wage country, because the outsourcing induces downward pressure on the negotiated wage.

\section{Optimal Outsourcing: The Long-Run Perspective}

So far we have restricted ourselves to a short run or medium run perspective, where the firm has committed itself to the magnitude of its outsourcing activities. We now turn to explore the initial stage of the decision making structure. At this stage the firm determines the investments into the establishment of outsourced production capacity. We are particularly interested in characterizing how the labour market imperfections impact on the equilibrium production mode, which, as we have analysed in the previous section, will have effects on the equilibrium unemployment.

In the long run the firm determines the magnitude of the outsourcing activities so as to maximize profits. The firm has rational expectations regarding the subsequent outcomes with respect to wage negotiation and employment and thus, the long-run 
production mode decision internalizes the effects of the share of outsourced production on wages and employment.

The long-run production mode is determined by the optimization problem

$$
\begin{gathered}
\max _{M} \pi=\quad R\left(M, L^{*}\right)-w^{N} L^{*}-c M-g(M) \\
\text { s.t. } \quad \Omega_{w}=0 \text { and } \pi_{L}=0 .
\end{gathered}
$$

The constraints capture that the production mode is set in anticipation of the subsequent determination of wages and employment. By applying the envelope theorem we find that the necessary first-order condition associated with the optimization problem (15) is given by

$$
\frac{\partial \pi}{\partial M}=\frac{\partial R}{\partial M}-\frac{\partial w^{N}}{\partial M} L^{*}-c-g^{\prime}(M)=0 .
$$

Next we briefly analyze the effects of labour market imperfections on optimal outsourcing. From (16) we can directly see that the presence of the imperfect labour market adds to the returns because outsourcing has wage-moderating effects, i.e. $\frac{\partial w^{N}}{\partial M}<0$, as was shown in Proposition 2 .

Condition (16) presents an implicit characterization of the optimal production mode. We can characterize how labour market imperfections impact on optimal outsourcing by reporting the following comparative statics result.

Proposition 4 Increased labour market imperfections promote outsourcing when $\sigma<1$.

Proof: See Appendix B

Proposition 4 captures the idea that the wage-moderating effect of outsourcing is stronger, the higher is the bargaining power of the labour union. 


\section{Conclusions}

We have studied the consequences of outsourcing for unemployment as well as the incentives associated with the introduction of outsourcing. We have shown that the wage elasticity of labour demand is increasing as a function of the share of outsourcing, which is a result consistent with existing empirical research (see Senses (2006)). Furthermore, we have demonstrated that a production mode with a higher proportion of outsourcing reduces the negotiated wage in the high-wage country with an imperfectly competitive labour market so that outsourcing reduces equilibrium unemployment. Finally, and importantly, we have characterized the optimal committed production mode by demonstrating that stronger labour market imperfections, measured by the relative bargaining power of labour unions, lead to a production mode with a higher share of outsourcing.

Our framework has abstracted from the wage dispersion and its potential relationship with various aspects of outsourcing activities. There exists evidence that high degrees of unionization and coverage of collective agreements compress the wage structure. Also higher degrees of centralization of collective bargaining reduce wage dispersion (see e.g. Rowthorn (1992), EEAG (2004) and Wallerstein (1999)). It is an important new research topic to analyze the relationships between outsourcing and the wage dispersion between high-skill and low-skill domestic workers. 


\section{References:}

Amiti, M. and S.-J. Wei (2004): Fear of Outsourcing: Is It Justified?, Centre for Economic Policy Research (CEPR) Discussion Paper No. 4719.

Arrow, K.J., H.B. Chenery, B.S. Minhas and R.M. Solow (1961): Capital-Labor Substitution and Economic Efficiency, Review of Economics and Statistics, XLIII, 225-250.

Business Week (2003): The New Global Shift, Cover Story, 3 February 2003.

Cahuc, P. and A. Zylberberg (2004): Labor Economics, MIT Press.

Danthine, J.-P. and J. Hunt (1994): Wage Bargaining Structure, Employment and Economic Integration, Economic Journal, 104, 528-541.

EEAG Report on the European Economy 2004. Chapter 3: Pay-Setting Systems in Europe: Ongoing Developments and Possible Reforms, Ifo Institute for Economic Research, 61-83.

Ethier, W.J. (2005): Globalization, Globalisation: Trade, Technology, and Wages, International Review of Economics and Finance, 14, 237-258.

Feenstra, R.C. and G.H. Hanson (1999): The Impact of Outsourcing and HighTechnology Capital on Wages: Estimates for the United States, 1979-1990, Quarterly Journal of Economics, 114(3), 907-940.

Glass, A. J. and K. Saggi (2001): Innovation and Wage Effects of International Outsourcing, European Economic Review, 45, 67-86.

Lommerud, K.E., F. Meland and O.R. Straume (2005): Can Deunionization Lead to International Outsourcing?, CESifo Working Paper No. 1545, September.

Nickell, S. and R. Layard (1999): Labor Market Institutions and Economic Performance, in Ashenfelter, O. and D. Card (eds): Handbook of Labor Economics, Volume 3C, 3029-3084.

Rishi, M. and S. Saxena (2004): Is Outsourcing Really as Bad as It Is Made Sound?, Working Paper, University of Pittsburgh.

Rowthorn, R.E. (1992): Centralization, Employment and Wage Dispersion, Economic Journal, 102, 506-523.

Senses, M. Z. (2006): The Effects of Outsourcing on the Elasticity of Labor Demand, CES Discussion Paper, Washington D.C. March.

Sinn, H.-W. (2006): Introduction, CESifo Forum 3/2006. 
Skaksen, J.R. (2004): International Outsourcing When Labour Markets Are Unionized, Canadian Journal of Economics, 37 (1), 78-94.

Skaksen, J.R. and J.R. Sorensen (2001): Should Trade Unions Appreciate Foreign Direct Investment?, Journal of International Economics, 55(2), 379-390.

Wallerstein, M. (1999): Wage-Setting Institutions and Pay Inequality in Advanced Industrial Societies, American Journal of Political Science, 43, 640-680.

Zhao, L. (1998): The Impact of Foreign Direct Investment on Wages and Employment, Oxford Economic Papers, 50, 284-301.

\section{Appendix A: Derivation of the wage elasticity of labour demand}

By using the production function we can write the wage elasticity of labour demand as follows

$$
\eta\left(\frac{M}{L}\right)=-\frac{L_{w} w}{L}=-\frac{R_{L}}{L R_{L L}},
$$

where the production function (1) with the diminishing returns to scale implies that $R_{L}=a \rho L^{-\frac{1}{\sigma}} X^{\frac{\sigma(\rho-1)+1}{\sigma-1}}, \quad X=(1-a) M^{\frac{\sigma-1}{\sigma}}+a L^{\frac{\sigma-1}{\sigma}} \quad$ and $R_{L L}=-\frac{a \rho}{\sigma} L^{-\frac{1}{\sigma}} X^{\frac{\sigma(\rho-1)+1}{\sigma-1}}\left[L^{-1}-X^{-1} L^{-\frac{1}{\sigma}} a[\sigma(\rho-1)+1]\right]$. Moreover, using these partial derivatives we have after some rearrangements

$$
-\frac{R_{L}}{L R_{L L}}=\frac{\sigma X}{X-a L^{\frac{\sigma-1}{\sigma}} a[\sigma(\rho-1)+1]}
$$

Using (A.1) and (A.2) the wage elasticity of substitution can after some rearrangements be written in the following way

$$
\eta\left(\frac{M}{L}\right)=\frac{a \rho L^{-\frac{1}{\sigma}} X^{\frac{\sigma(\rho-1)+1}{\sigma-1}} \sigma}{a \rho L^{-\frac{1}{\sigma}} X^{\frac{\sigma(\rho-1)+1}{\sigma-1}}\left[1-X^{-1} L^{\frac{\sigma-1}{\sigma}} a[\sigma(\rho-1)+1]\right]}=\frac{\sigma X}{X-L^{\frac{\sigma-1}{\sigma}} a[\sigma(\rho-1)+1]} .
$$

This in turn can be simplified to

$$
\eta\left(\frac{M}{L}\right)=\frac{\sigma\left(1+\frac{1-a}{a}\left(\frac{M}{L}\right)^{\frac{\sigma-1}{\sigma}}\right)}{\left[\sigma(1-\rho)+\frac{1-a}{a}\left(\frac{M}{L}\right)^{\frac{\sigma-1}{\sigma}}\right]} .
$$


QED.

\section{Appendix B: Optimal outsourcing and labour market imperfections}

According to (16) the optimal production mode is characterized by

$$
\frac{\partial \pi}{\partial M}=\frac{\partial R}{\partial M}-\frac{\partial w^{N}}{\partial M} L^{*}-g^{\prime}(M)=0
$$

What is the effect of the union bargaining power on optimal outsourcing? The bargaining power affects the optimal outsourcing through $\frac{\partial w^{N}}{\partial M}$, which is negative from Proposition 2. Differentiating the equation (10) with respect to $\beta$ gives

$\frac{\partial}{\partial \beta}\left[\frac{\partial w^{N}}{\partial M}\right]=Y^{-3} b\left\{\begin{array}{l}-Y\left[2 \beta \eta_{M}+(1-2 \beta) \frac{1-\sigma}{\sigma} \frac{a}{1-a}\left(\frac{M}{L}\right)^{\frac{1-2 \sigma}{\sigma}}\right] \\ +2\left[(\eta-1)-\frac{a}{1-a}\left(\frac{M}{L}\right)^{\frac{1-\sigma}{\sigma}}\right]\left[\beta^{2} \eta_{M}+\beta(1-\beta) \frac{1-\sigma}{\sigma} \frac{a}{1-a}\left(\frac{M}{L}\right)^{\frac{1-2 \sigma}{\sigma}}\right]\end{array}\right\}$

where $Y=\beta(\eta-1)+(1-\beta) \frac{a}{1-a}\left(\frac{M}{L}\right)^{\frac{1-\sigma}{\sigma}}>0$ and $\eta_{M}$ has been expressed in (5).

After some rearrangements (B2) can be written as

$\frac{\partial}{\partial \beta}\left[\frac{\partial w^{N}}{\partial M}\right]=Y^{-3} b \frac{a}{1-a} \frac{1-\sigma}{\sigma}\left(\frac{M}{L}\right)^{\frac{1-2 \sigma}{\sigma}}\left[\beta(\eta-1)-(1-\beta) \frac{a}{1-a}\left(\frac{M}{L}\right)^{\frac{1-\sigma}{\sigma}}\right]$

where $\quad \eta-1=\frac{\sigma \rho+(\sigma-1) \frac{1-a}{a}\left(\frac{M}{L}\right)^{\frac{\sigma-1}{\sigma}}}{\left[\sigma(1-\rho)+\frac{1-a}{a}\left(\frac{M}{L}\right)^{\frac{\sigma-1}{\sigma}}\right]}$. Using this the expression $K=\left[\beta(\eta-1)-(1-\beta) \frac{a}{1-a}\left(\frac{M}{L}\right)^{\frac{1-\sigma}{\sigma}}\right]$ can after some rearrangements be written as follows

$$
K=\beta(\sigma \rho-1)+\frac{a}{1-a}\left(\frac{M}{L}\right)^{\frac{\sigma-1}{\sigma}} \beta(\sigma-1)-\frac{a}{1-a}\left(\frac{M}{L}\right)^{\frac{1-\sigma}{\sigma}}(1-\beta) \sigma(1-\rho) .
$$


Hence $\frac{\partial}{\partial \beta}\left[\frac{\partial w^{N}}{\partial M}\right]<0$. Because we know that $-\frac{\partial w^{N}}{\partial M} L^{*}$ is positive it follows that higher bargaining power of the trade union will add to the returns from outsourcing. As the costs of establishing capacity for outsourced production are increasing and convex, we can conclude that the increased labour market imperfections mean that the first-order condition (16) will be satisfied for higher M. QED. 